\title{
latrogenic perirenal urinary extravasation following percutaneous coronary intervention
}

\author{
Maciej Sałagaj', Artur Dębski', Paweł Tyczyński', Tomasz Oleksiuk², Adam Witkowski \\ 'Department of Interventional Cardiology and Angiology, National Institute of Cardiology, Warszawa, Poland \\ ${ }^{2}$ Department of Radiology, Mazovian Brodnowski Hospital, Warszawa, Poland
}

Correspondence to: Paweł Tyczyński, MD, PhD, Department of Interventional Cardiology and Angiology, Institute of Cardiology, Alpejska 42 04-628 Warszawa, Poland, phone: +48 223434272 e-mail: medykpol@wp.pl Copyright by the Author(s), 2021

Kardiol Pol. 2021; 79 (7-8): 879-880 DOI: 10.33963/KP.a2021.0006 Received: March 9, 2021 Revision accepted: April 29, 2021 Published online: May 13, 2021
Urinary extravasation is a rarely diagnosed phenomenon, the most frequent cause of which is ureteral stone obstruction and malignant tumors. However, it can also be an iatrogenic complication of medical procedures. Increasing urinary pressure inside the pelvicalyceal system due to a prolonged procedure may lead to spontaneous rupture of the renal fornix, which is the most susceptible part of the renal collecting system to extravasation. Proper differentiation and management are difficult due to the absence of characteristic symptoms. Herein, we report on a 45-year-old male patient with multi-vessel coronary artery disease, who was admitted for percutaneous coronary intervention $(\mathrm{PCl})$ due to chronic total occlusion of the marginal branch of the left coronary artery, and significant stenosis of the right coronary artery. Intravenous fluids $(0.9 \%$ Natrium Chloratum, total amount of $1000 \mathrm{ml}$ ) were administered pre- and intra-procedure to minimize the risk of contrast-induced nephropathy. A successful $\mathrm{PCl}$ with drug-eluting stent implantation in two coronary arteries was performed. The total amount of contrast agent (lomeron 300, Bracco Imaging, Konstanz, Germany) used was $200 \mathrm{ml}$. Thirty minutes after the intervention the patient experienced intense pain along the right side of the body resembling renal colic. An emergency abdominal ultrasound showed dilation of the pelvicalyceal system of the right kidney (pelvis $17 \mathrm{~mm}$, calyces $14 \mathrm{~mm}$ ). No obstruction of the urinary tract was visible. An abdominal scan using delayed phase computed tomography $(\mathrm{CT})$ revealed the presence of a small volume of contrasted urine in the upper part of the right renal hilum, upper-medial perirenal fat, and along the proximal right ureter and inferior retrorenal fascia (Figure 1). Urological consultation led to the diagnosis of perirenal urinary extravasation. A Foley catheter was inserted into the bladder, and prophylactic therapy with ciprofloxacin was initiated with a good outcome.

The presented case illustrates a rare iatrogenic complication during an unrelated procedure. To our knowledge, no such urinary extravasation following $\mathrm{PCl}$ has been reported

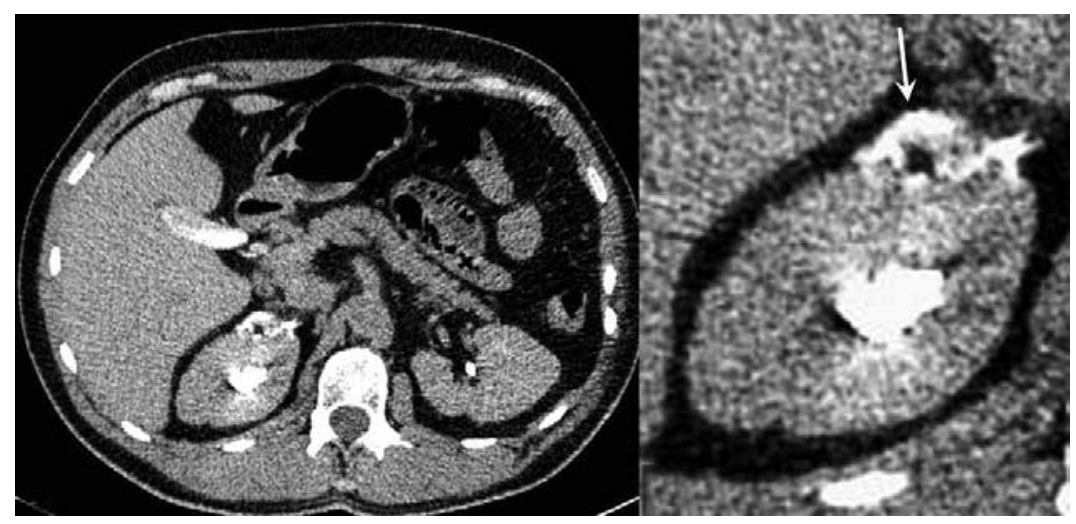

Figure 1. Computed tomography of the abdomen in delayed phase scan. A. A small volume of contrasted urine in the upper part of the right renal hilum. B. Magnification $2.6 \times$ of the image with a focus on contrasted urine pointed by the arrow 
previously. Intensive, intravenous fluid administration during prolonged $\mathrm{PCl}$ and urine retention were the clear causes of this complication. There are two types of urine extravasation beyond the pelvicalyceal system: subcapsular and perirenal (as in our case), both of which may be unior bilateral [1]. Increased renal pressure up to $35-40 \mathrm{~cm}$ $\mathrm{H}_{2} \mathrm{O}$ [2] may cause ruptures of the fornices of the renal calyces with subsequent perirenal extravasation of urine which collects between the renal capsule and fascia [3]. The main clinical symptom is sudden, severe pain in the lumbar region. No specific symptoms allow for early diagnosis of urine leakage out of the urinary collecting system. Once urinary extravasation is suspected, three main diagnostic methods can be used: conventional ultrasound, urography, or CT [4], although these are complimentary; ultrasound demonstrated the only dilation of the pelvicalyceal system without urine leakage, which was revealed with CT in our patient. Removal of any obstruction of the urinary tract and conservative treatment with antibiotic prophylaxis are usually sufficient to facilitate a positive outcome [5].

\section{Article information}

Conflict of interest: None declared.

Open access: This article is available in open access under Creative Common Attribution-Non-Commercial-No Derivatives 4.0 International (CC BY-NC-ND 4.0) license, allowing to download articles and share them with others as long as they credit the authors and the publisher, but without permission to change them in any way or use them commercially. For commercial use, please contact the journal office at kardiologiapolska@ptkardio.pl.

How to cite: Sałagaj M, Dębski A, Tyczyński P, et al. latrogenic perirenal urinary extravasation following percutaneous coronary intervention. Kardiol Pol. 2021; 79(7-8): 879-880, doi: 10.33963/KP.a2021.0006.

\section{REFERENCES}

1. Puri A, Bajpai M, Gupta AK. Bilateral spontaneous perinephric urinomas: case report and review of the literature. Urology. 2004; 64(3): 590-591, doi: 10.1016/j.urology.2004.04.057, indexed in Pubmed: 15351610.

2. Sala $S$, Bighi $S$, Giombi $A$, et al. Perirenal urinary extravasation: imaging and therapy. Report of two cases. Radiol Med. 2002; 103(1-2): 126-129, indexed in Pubmed: 11859310.

3. Kryst P, Milewski JB, Gołębiewski J, et al. Urinary leak in the retroperitoneal and perirenal space, diagnosis and treatment [Polish]. Urol Pol. 1994;47(3).

4. Piwoński M, Kucharczyk B. Efficiency of imaging methods (urography, CT contrast-enhanced) in acute stage of ureterolithiasis-interpretation problems based on description case and bibliography review. Przegl Lek. 2013; 70(6): 407-410, indexed in Pubmed: 24052980.

5. Akpinar H, Kural AR, Tüfek I, et al. Spontaneous ureteral rupture: is immediate surgical intervention always necessary? Presentation of four cases and review of the literature. J Endourol. 2002; 16(3): 179-183, doi: 10.1089/089277902753716160, indexed in Pubmed: 12028629. 